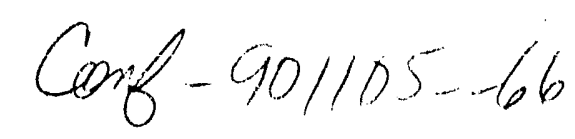

\title{
NEUTRON IRRADIATED URANIUM SILICIDES STUDIED BY NEUTRON . DIFFRACTION AND RIETVELD ANALYSIS
}

\author{
R. C. Birtcher, M. H. Mueller and J. W. Richardson, Jr. CONF-901105--66 \\ Argonne National Laboratory \\ Argonne, IL 60439 \\ DE9 1006502
}

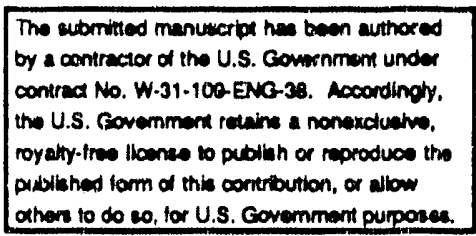

DISCLAIMER

\begin{abstract}
This report was prepared as an account of work sponsored by an agency of the United States Government. Neither the United States Government nor any agency' thereof, nor any of their employees, makes any warranty, express or implied, or assumes any legal liability or responsibility for the accuracy, completeness, or usefulness of any information, apparatus, product, or process disclosed, or represents that its use would not infringe privately owned rights. Reference herein to any specific commercial product, process, or service by trade name, trademark, manufacturer, or otherwise does not necessarily constitute or imply its endorsement, recommendation, or favoring by the United States Government or any agency thereof. The views and opinions of authors expressed herein do not necessarily state or reflect those of the United States Government or any agency thereof.
\end{abstract}

Submitted to the Materials Research Society 1990 Fall Meeting, Nov. 26-Dec. 1, 1990, Boston, MA.

"Work supported by the U. S. Department of Energy, BES-Materials Sciences, under Contract W-31-109-Eng-38 and the NSF.

\section{MASTER}




\title{
NEUTRON IRRADIATED URANIUM SILICIDES STUDIED BY NEUTRON DIFFRACTION AND RIETVELD ANALYSIS
}

\author{
R. C. BIRTCHER*, M. H. MUELLER* and J. W. RICHARDSON, Jr." \\ "Argonne National Laboratory, Argonne, IL 60439
}

\section{INTRODUCTION}

The irradiation behavior of high-density uranium silicides has been a matter of interest to the nuclear industry for use in high power or low enrichment applications. Transmission electron microscopy studies have found that heavy ion bombardment renders $\mathrm{U}_{3} \mathrm{Si}$ and $\mathrm{U}_{3} \mathrm{Si}_{2}$ amorphous at temperatures below about $250 \mathrm{C}[1]$, and that $\mathrm{U}_{3} \mathrm{Si}$ becomes mechanically unstable suffering rapid growth by plastic flow $[2,3]$. In this present work, crystallographic changes preceding amorphization by fission fragment damage have been studied by high-resolution neutron diffraction as a function of damage produced by uranium fission at room temperature. Initially, both silicides had tetraconal crystal structures. Crystallographic and amorphous phases were studied simultaneously by combining conventional Rietveld refinement of the crystallographic phases with Fourierfiltering analysis of the non-crystalline scattering component [4].

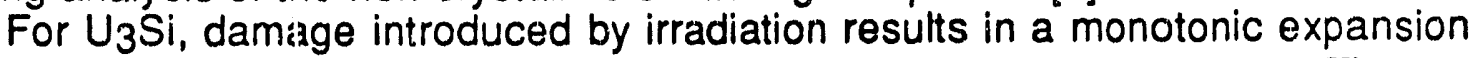
of the a-axis and contraction of the r-axis with increasing irradiation dose. The net effect is an expansion of the tetragonal unit cell. The expansion, coupled with a concomitant shift of midplane/midcell uranium atoms to symmetric positions, would result in a new cubic unit cell of the CuzAu type. The phase transformation appears to be homogeneous and continuous without indication of coexistence of the initial and final phases. For $\mathrm{U}_{3} \mathrm{Si}_{2}$, both the a- and $\mathrm{c}$-axes contract with increasing irradiation dose. Positional shifts of both uranium and silicon atoms continuously transform the $\mathrm{U}_{3} \mathrm{Si}_{2}$ toward a yet undetermined crystal structure. For both silicides, increases in background scattering reflect damage accumulation and/or amorphization. Damage in $U_{3} S i$ saturates after a dose of 0.02 displacements per atom (dpa) and amorphization begins after an expansion of 1 at.\% at $0.05 \mathrm{dpa}$.

\section{EXPERIMENTAL}

Powdered $\mathrm{U}_{3} \mathrm{Si}$ and $\mathrm{U}_{3} \mathrm{Si}_{2}$ specimens were fabricated from high purity $\mathrm{Si}$ and highly depleted Uranium, 0.022 at $\%{ }^{235} \mathrm{U}$. The high dose irradiation behaviors of these powders, roll-bounded between aluminum plates, have been previously studied [2]. For this study, each powder, 50 to $150 \mu \mathrm{m}$ in diameter, was doubly encapsulated in thin wall Vanadium cans that had been evacuated and filled with He gas. The $U_{3}$ Si specimen also contained precipitates of $U_{3} S_{2}$ (<15 volume \%) and the uranium oxides $\mathrm{UO}$ and $\mathrm{UO}_{2}(<5$ volume $\%)$ introduced by vacuum annealing.

Neutron irradiations were performed at IPNS in a room temperature facility located adjacent to the neutron source [5]. Neutrons are produced as the result of $500 \mathrm{MeV}$ protons striking a ${ }^{235} \mathrm{U}$ target. The neutron spectrum for this facility is characteristic of a reactor neutron spectrum with the addition of neutrons having energies up to $500 \mathrm{MeV}$. In these specimens, damage was produced primarily by uranium fission in a manner identical to damage production in operating nuclear reactor fuel. The nuclear-reaction cross sections for fast and thermal fission were determined by standard activation techniques to give a burn up rate of $5.4 \times$ 
10-27/proton [6]. The irradiations were performed in small steps, ${ }^{235} \mathrm{U}$ burn-up $<3 \times$ $10^{-8}$, in order to closely follow changes in the crystal structure, and total burn-ups are about $1 \times 10^{-6}$. The number of defects per fission has been calculated to be $7.8 \times 10^{4}$ [7], and total damage concentrations are about $0.07 \mathrm{dpa}$.

After each irradiation and appropriate radioactivity cool-down, a powder pattern was measured on the General Purpose Powder Diffractometer (GPPD) at the Intense Pulsed Neutron Source (IPNS) and the data were analyzed using the Rietveld profile refinement technique [8]. Details of data collection and analysis are given in a recent paper [Y].

\section{'RESULTS}

The crystal structure refinements of unirradiated $\mathrm{U}_{3} \mathrm{Si}$ and $\mathrm{U}_{3} \mathrm{Si}_{2}$, including the $U_{3} \mathrm{Si}_{2}$ precipitates in $U_{3} \mathrm{Si}$, agree with those previously obtained from $X$-ray diffraction $[10,11]$. Repeated irradiation produced structural changes in both alloys which resulted in a broadening and shifting of the Bragg peaks.

Unirradiated $U_{3} S i$ is tetragonal, space group $14 / \mathrm{mcm}$, with $a=6.0358(1), c=$ $8.6925(1) \AA, c / a=1.440$ and 16 atoms per unit cell. There are: $4 U_{1}$ at $\pm(0,1 / 2,1 / 4)$; $8 U_{\| 1}$ at $\pm(x, x+1 / 2,0)$ with $x=0.2251(1)$ and $4 \mathrm{Si}$ at $(0,0,1 / 4)$. The base layer $(z=0)$ contains only uranium atoms, the next layer $(z=1 / 4)$ contains an equal number of uranium and silicon atoms, and the sequence repeats. The layer at $z=1 / 2$ ( $U$ only) is rotated slightly relative to the base layer. This structure can be viewed as pseudo-cubic, in that if the $U_{\|}$are shifted such that $x=1 / 4$ and simultaneously the axial ratio $(c / a)$ is reduced to $\sqrt{2}, U_{3}$ Si would have the cubic $\mathrm{Cu}_{3} \mathrm{Au}$ type structure $\left(a_{C}=a_{\mathrm{T}} / \sqrt{2}=C_{T} / 2\right)$. This transformation also occurs upon heating to $1038 \mathrm{~K}$ [12].

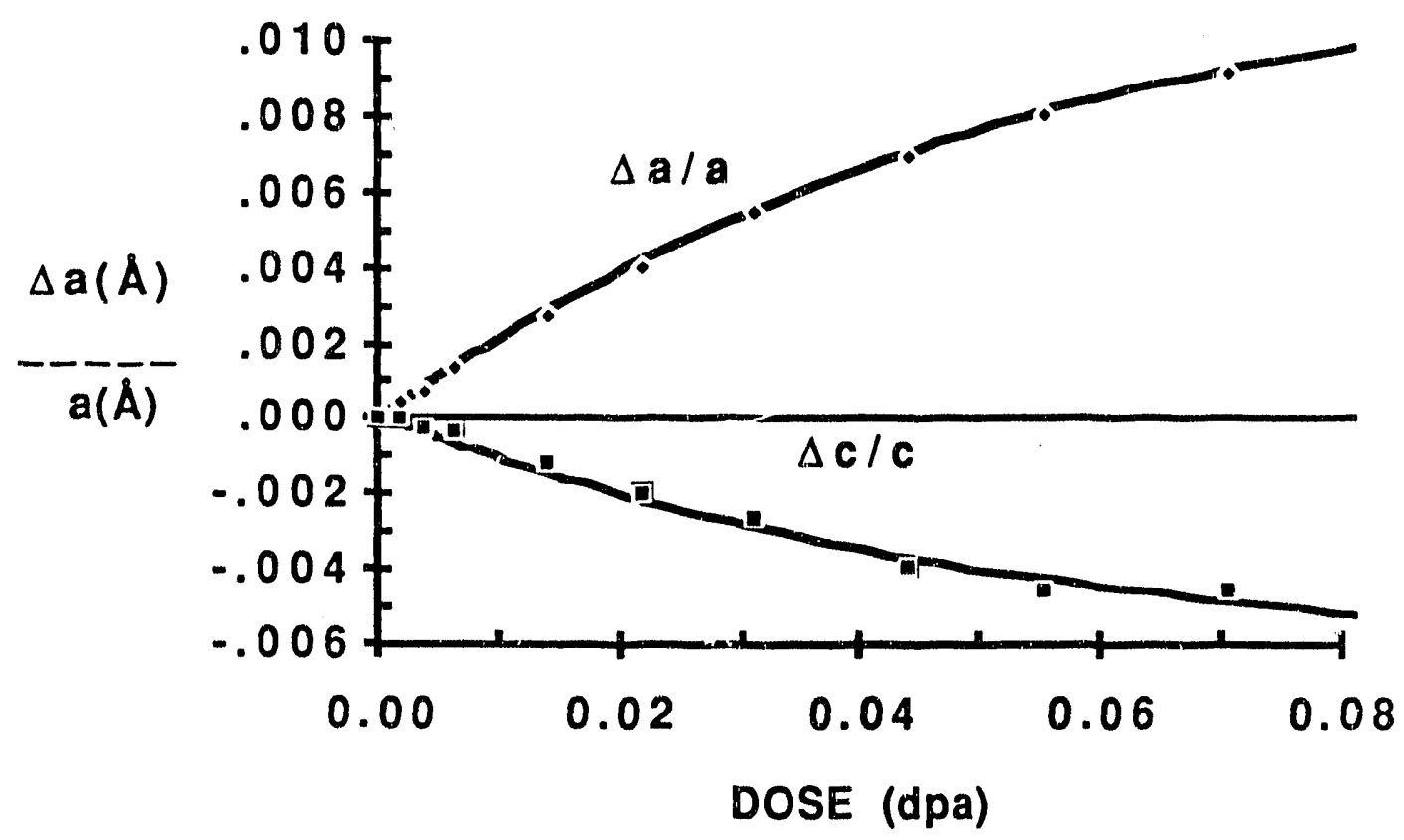

Fig 1. Variation of the lattice parameters of $\mathrm{U}_{3} \mathrm{Si}$ with damage.

Lattice parameter change: produced by neutron irradiation of $\mathrm{U}_{3} \mathrm{Si}$ are shown in Fig 1. After 0.07 displacements per atom, the a-axis increased by $1 \%$ and the c-axis decreased by $0.5 \%$, resulting in a net unit cell volume increase of $1.4 \%$. In addition, $U_{\| 1}$ is approaching the idealized $\mathrm{Cu}_{3} \mathrm{Au}$ position 
$(1 / 4,3 / 4,0)$, the $(220)_{T}$ and $(004)_{T}$ reflections are gradually converging to the cubic $(200)_{C}$, diffraction peaks broaden, and the diffuse background is significantly increased. The cubic transformation is illustrated in Fig. 2 by the convergence of the $(220)_{T}$ and $(004)_{T}$ reflections with increasing damage. Extrapolation of these peaks positions to total convergence yields the high temperature, "cubic-phase lattice parameter. These peak shifts indicate the accumulation of a homogeneous lattice strain and no direct formation of the cubic phase within the small volumes damaged by the fission fragments. Such direct formation of cubic material would be indicated by the growth of a [002] diffraction peak at $2.156 \AA$ rather than the merging of the tetragonal peaks. In addition at the highest dose of $0.086 \mathrm{dpa}$, the scattering contains less than $4 \%$ of the $[220]_{c}$ diffraction peak found for unirradiated material. The homogeneous nature of the transformations may be enhanced by the powder specimen which consists of single-crystal particles between 50 and $150 \mu \mathrm{m}$ in diameter. Fig. 3 shows the variation with damage of the ratio of background scattering intensity to peak intensity over the range shown in Fig. 2 . The initial

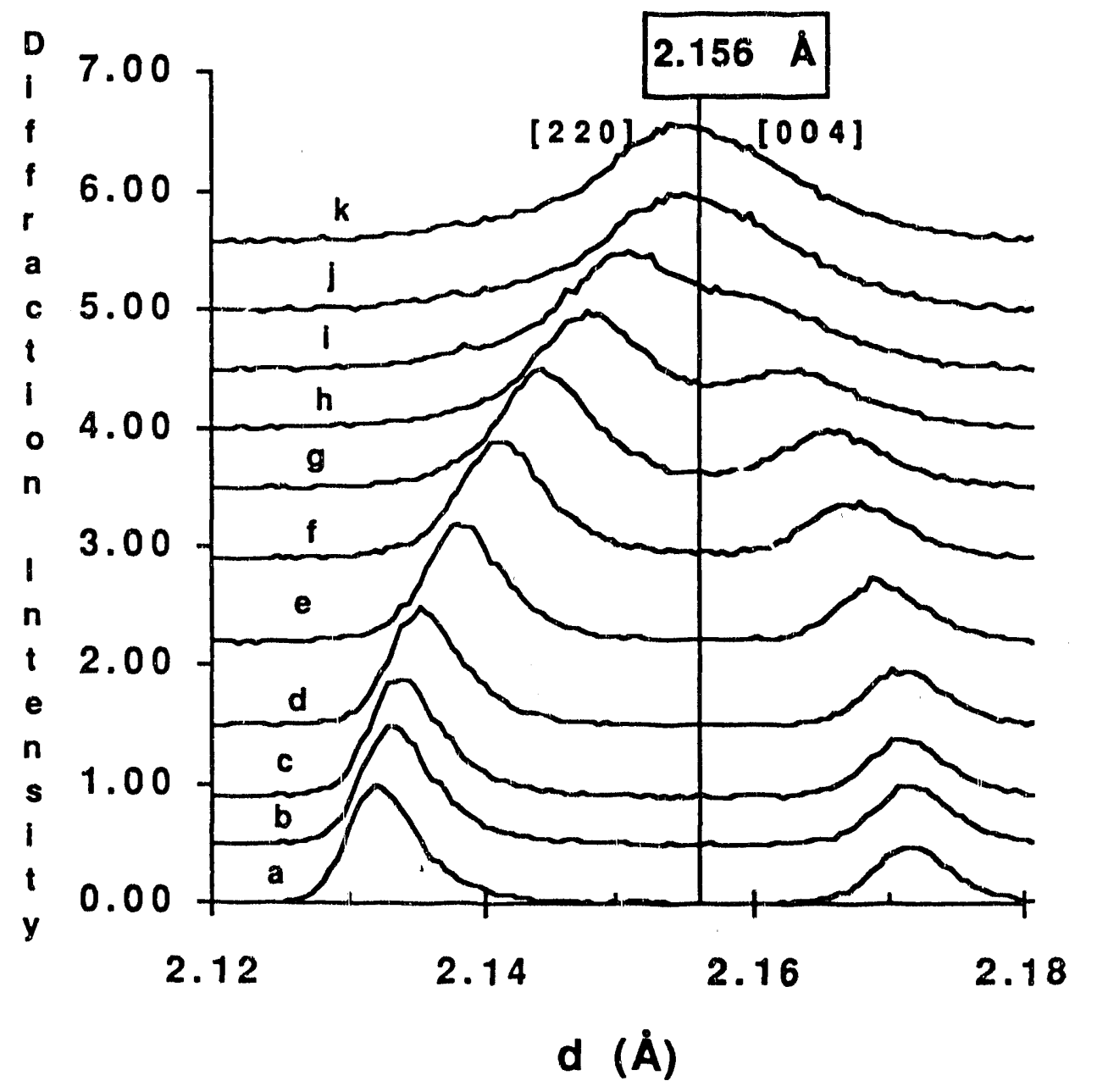

Fig 2. Changes in the $(220)_{T}$ and $(004)_{T}$ reflections of $U_{3} S i$ produced by neutron irradiation. Background intensities have been subtracted, and peak intensities have been normalized to unity. The different curves correspond to damage levels of: a $0 ; b .002 ; c .004 ; d .006 ; \theta .014 ;\{.022 ; \mathrm{g}$ $.031 ; h .044 ; \mathrm{i} .055 ; j .071$ and $k .086 \mathrm{dpa}$. The vertical line at $2.157 \AA$ is half the lattice parameter of the high temperature cubic phase. 
increase is thought to be due to defect accumulation while the large increase after $0.05 \mathrm{dpa}$ is thought to be due to amorphization. The saturation of the initial increase occiurs at a dose similar to that found for defect saturation in fission fragment irradiated metals [13]. The large increase in background scattering occurs in the dose regime required for amorphization of $U_{3} S i$ by heavy ions [3]. The Debye-Waller factors for all atomic sites increases with irradiation although the RMS values for $\mathrm{Si}$ atoms are somewhat less than for the $U$ atoms. This may be indicative of deviations, static or dynamic, of $U$ atoms from their ideal locations. In summary, neutron irradiation transforms the tetragonal crystal structure to either the high temperature cubic form and/or to an amorphous form.

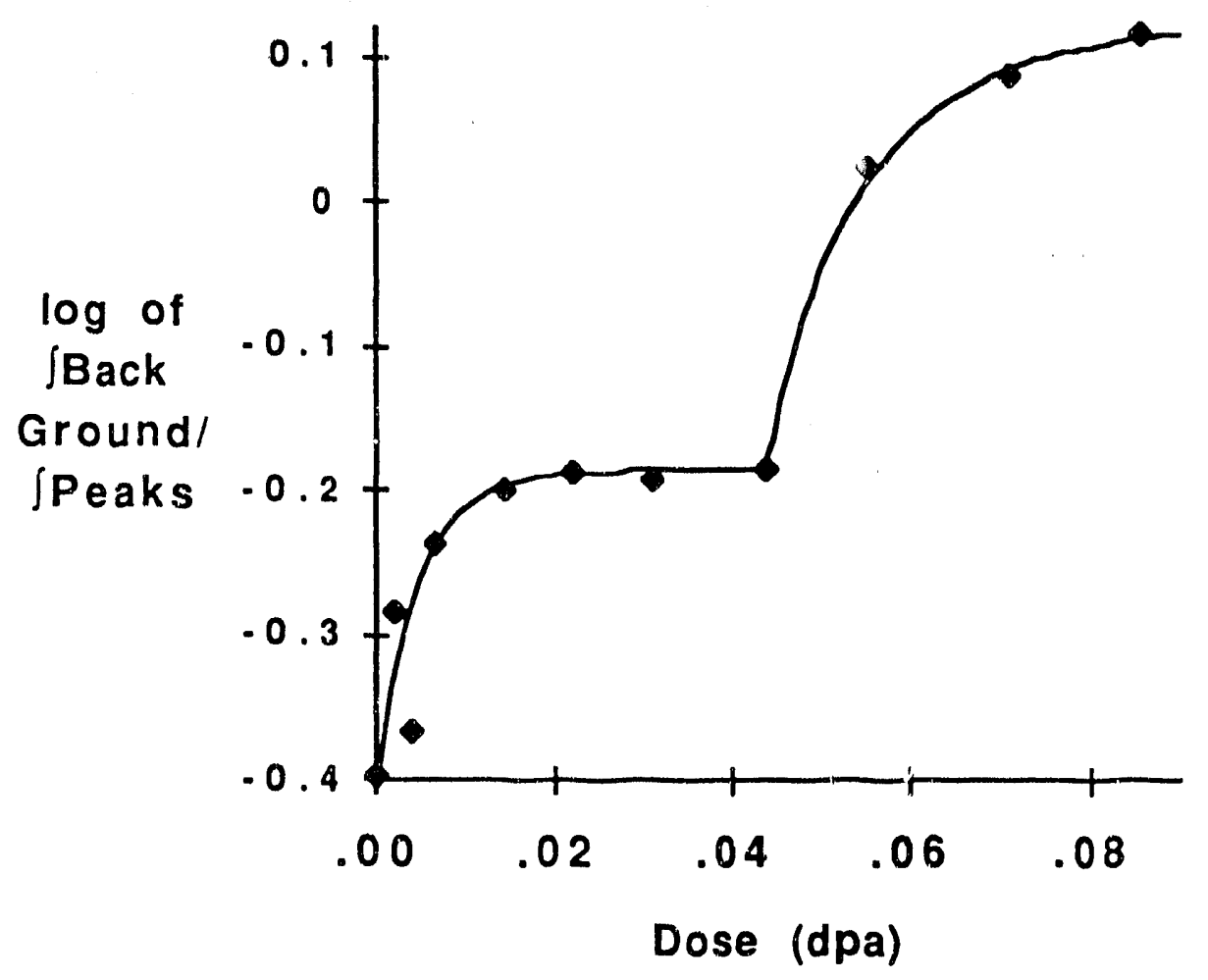

Fig 3. Variation of the ratio of integrated background to $(220)_{T}$ and $(004)_{T}$ peak intensities for $\mathrm{U}_{3} \mathrm{Si}$.

Unirradiated $\mathrm{U}_{3} \mathrm{Si}_{2}$ is tetragonal, space group $\mathrm{P} 4 / \mathrm{mbm}$, with $\mathrm{a}=7.33101 \AA$, $c=3.90092 \AA, c / a=0.532$ and 10 atoms per unit cell. There are $U_{1}$ atoms at $(0,0,0)$ and $(1 / 2,1 / 2,0) ; 4 U_{\|}$atoms at $\pm(x, x+1 / 2,1 / 2)$ with $x=0.18186$ and 4 Si at $\pm\left(x^{\prime}\right.$, $\left.x^{\prime}+1 / 2,0\right)$ with $x^{\prime}=0.38383$. Variations of the lattice parameters as a function of dose are shown in Fig. 4. There is little change in the $c$-axis while there is a strong contraction of the a-axis. The $\mathrm{U}_{3} \mathrm{Si}_{2}$ unit cell volume decreases during irradiation, in contrast to the increase observed for $\mathrm{U}_{3} \mathrm{Si}$. There are large out-of-plane displacements of $U_{1}$ atoms along the [001] direcion in all forms of the $U_{3} \mathrm{Si}_{2}$, shown in Fig. 5: both unirradiated and irradiated; pure phase and second phase in $\mathrm{U}_{3} \mathrm{Si}$. These displacements increase from an initial value of $0.26 \AA$ at a rate of $2.7 \AA / \mathrm{dpa}$ during irradiation. It is conceivable that the huge displacement parameter represents an average of random static displacements. With irradiation, the $U_{\| 1}$ site moves toward $(0,1 / 2,1 / 2)$ and pairs of $\mathrm{Si}$ atoms move away from each other and toward $(1 / 4,1 / 4,0)$ sites. Completion of this process would result in two uranium 
atoms occupying the same site or in formation of a phase with incorrect stoichiometry. Other $\mathrm{U}_{3} \mathrm{Si}_{2}$ phases have not been observed in thermodynamic studies.

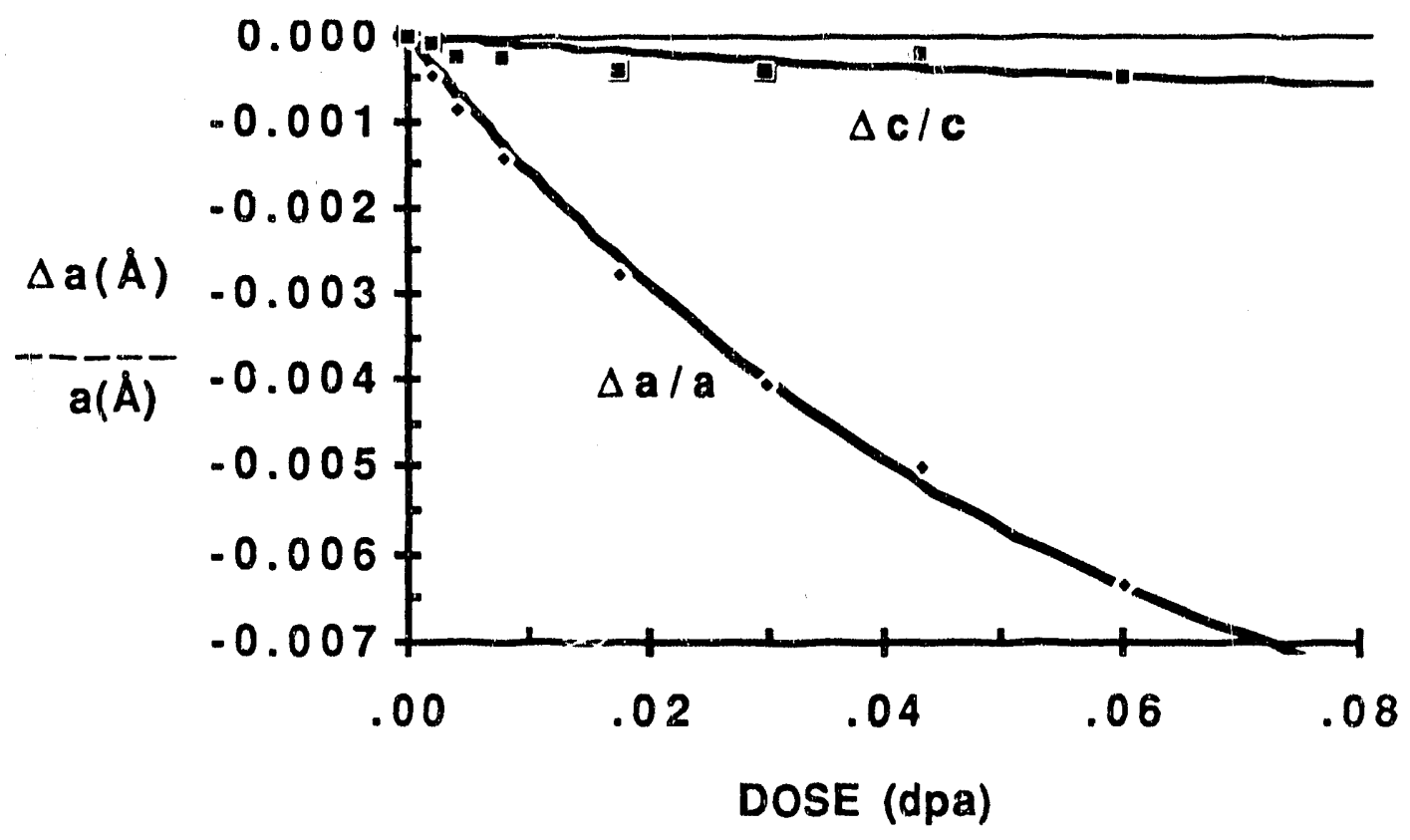

Fig 4. Variation of the lattice parameters of $\mathrm{U}_{3} \mathrm{Si}_{2}$ with damage.

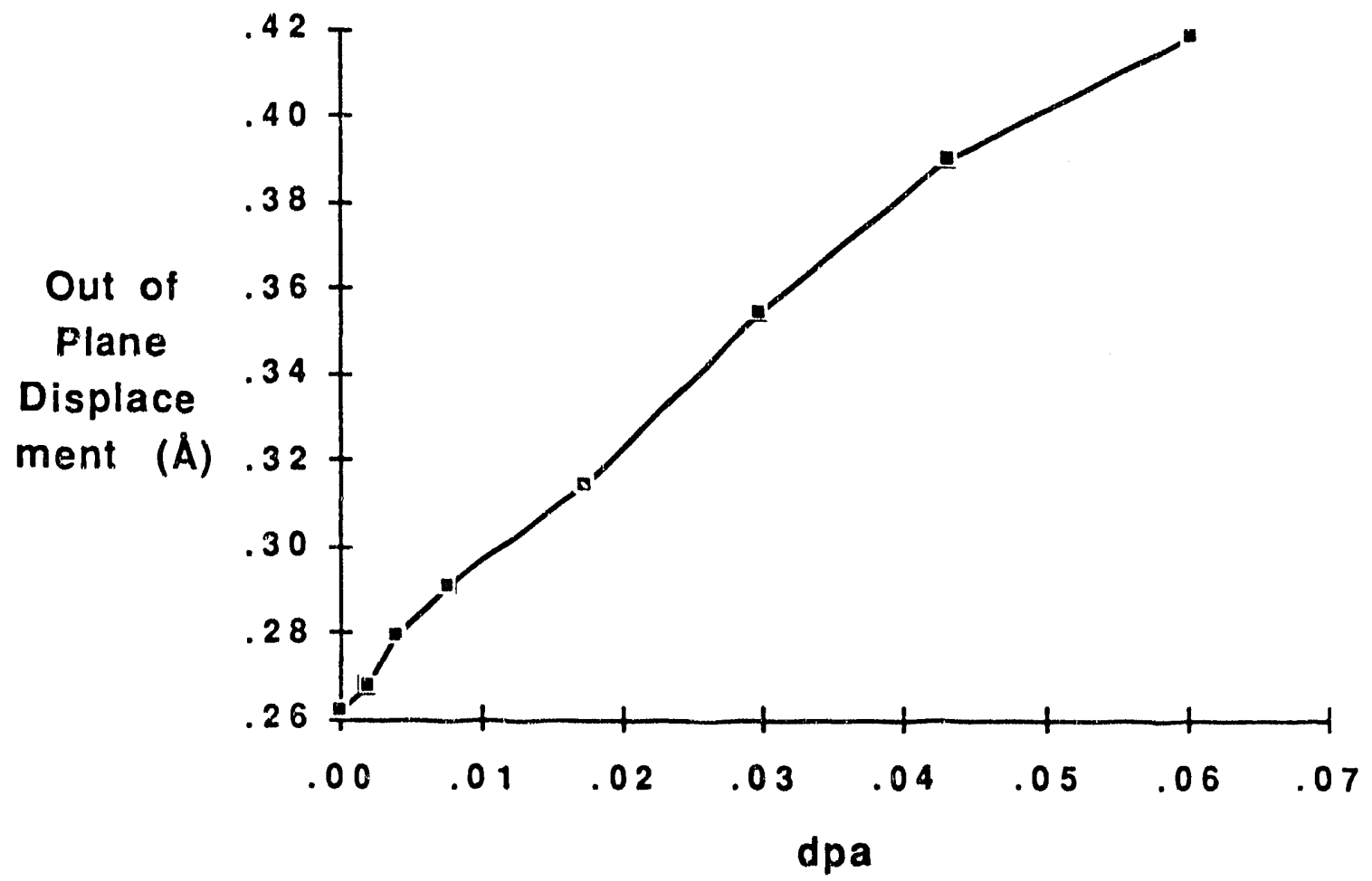

Fig 5. Variation of the out of plane displacement of the $U_{1}$ atom position in $\mathrm{U}_{3} \mathrm{Si}_{2}$. 
Radiation damage accumulation in $U_{3} S i$ and $U_{3} S_{2}$ has been monitored with neutron diffraction. During irradiation, the lattice of $U_{3} S i$ expands while the lattice of $\mathrm{U}_{3} \mathrm{Si}_{2}$ contracts. Both seem to be approaching a common atomic density. In both materials, lattice parameter changes and diffraction peak shifts indicate the occurrence of a homogeneous transformation from initially tetragonal structures towards cubic structures. The cubic structures are not directly produced by the defect cascades. Increases in background scattering indicate damage saturation after about $0.01 \mathrm{dpa}$ and growth of an amorphous phase at damage levels above $0.04 \mathrm{dpa}$. The defect saturation dose is in agreement with the saturation dose of fissicn-fragment damage in metals [13], and the amount of damage required for amorphization of $U_{3} \mathrm{Si}$ is in agreement with the amorphization dose when damage is produced by high-energy heavy ions [3]. A possible explanation of the homogeneous phase transformation and amorphization behavior is that individual fission-fragment events damage a volume of material while directly amorphizing a smaller volume. Volume changes $(>2 \%)$ in the small amorphous volumes introduce long range strains which are responsible for the homogeneous change of the lattice parameter.

\section{ACKNOWLEDGEMENTS}

We would like to thank T. L. Scott and J. M. Jezisek for assistance in radioactive specimen handling and $R$. L. Hitterman assistance in data collection. Work supported by the U. S. Department of Energy, BES-Materials Sciences, under Contract W-31-109-Eng-38.

\section{REFERENCES}

[1] D. G. Walker, J. Nucl. Mat. 37, 48 1970).

[2] G. L. Hofman, J. Nucl. Mat. 140, 256 (1986).

[3] R. C. Birtcher, C. W. Allen, L. E. Rehn and G. L. Hofman, J. Nucl. Mater. 152, 73 (1988).

[4] J. W. Richardson, Jr. and J. Faber, Jr., Adv. X-ray anal. 29, 143 (1985).

[5] R. C. Birtcher, T. H. Blewitt, M. A. Kirk, T. L. Scott, B. S. Brown and

L. R. Greenwood, J. Nucl. Mater. $108 \& 109,3$ (1982).

[6] L. R. Greenwood, private communication.

[7] D. M. Parkin and R. O. Elliott, Nucl. Inst. Meth. B16, 193 (1986).

[8] H. M. Rietveld, J. Appl. Cryst. 2, 65 (1969).

[9] J. D. Jorgensen, J. Faber, Jr., J. M. Carpenter, R. K. Crawford, J. R. Hauman, R. L. Hitterman, R. Kleb, G. E. Ostrowski, F. J. Rotella and T. G. Worlton, J. Appl. Cryst. 21, 321 (1989).

[10] W. H. Zachariasen, Acta Cryst. 2, 94 (1949).

[11] G. Kirnmel and S. Nadiv, Acta Cryst. B31, 1351 (1975).

[12] P. L. Blum, G.Silvestro and H. Vangoyan, C. R. Acad. Sci. 260, 5538 (1964).

[13] R. C. Birtcher, R. S. Averback and T. H. Blewitt, J. Nucl. Mat. 75,167 (1978). 

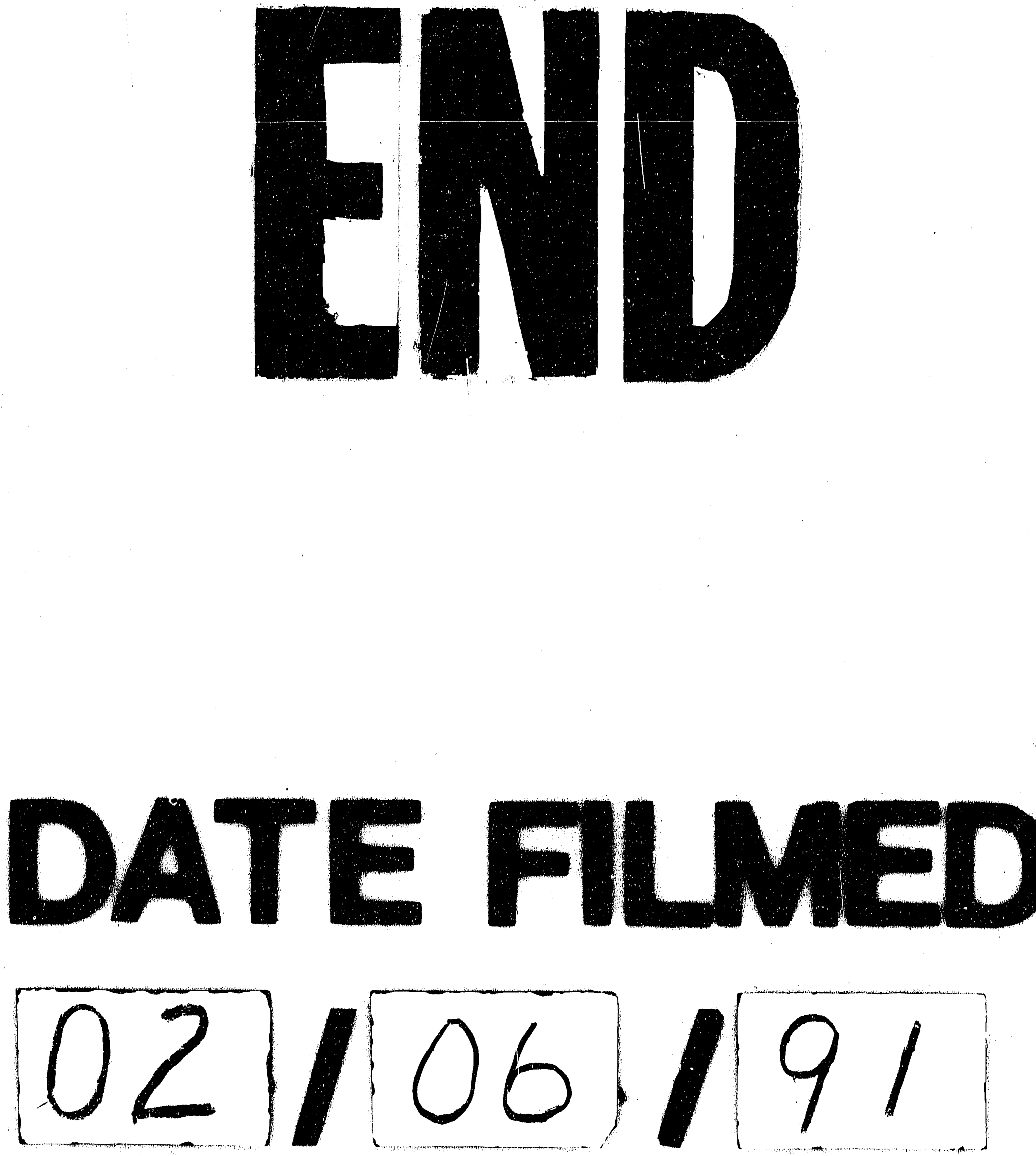
